Instituto Internacional de Investigación y Desarrollo Tecnológico Educativo INDTEC, C.A.

DOI: https://doi.org/10.29394/Scientific.issn.2542-2987.2021.6.21.12.237-251

OAI-PMH: http://www.indteca.com/ojs/index.php/Revista Scientific/oai

Ensayo Original / Original Essay

\title{
Análisis del contexto económico en el Perú a partir del COVID-19
}

\author{
Autores: Carlos Antonio Rosales Enríquez \\ Universidad Tecnológica del Perú, UTP \\ crosales1000@gmail.com \\ Chimbote, Perú \\ https://orcid.org/0000-0003-3739-3007 \\ Mary Sabeth Álvarez Silva \\ Universidad Tecnológica del Perú, UTP \\ marysabethalvarez@hotmail.com \\ Chimbote, Perú \\ https://orcid.org/0000-0001-7023-2075 \\ Ingrid Cristina Lam Flores \\ Universidad Tecnológica del Perú, UTP \\ ilamflo@hotmail.com \\ Chimbote, Perú \\ https://orcid.org/0000-0002-6215-0173
}

\section{Resumen}

El presente ensayo da a conocer un análisis de la situación económica del Perú en el contexto del inicio de la pandemia de la COVID-19, ante el establecimiento de una cuarentena total obligatoria implementada por el gobierno, cuantiosas empresas de distintos sectores debieron suspender temporalmente sus operaciones, etapa que generó la ruptura de la cadena de pagos y por consiguiente que numerosas empresas y familias no generen ingresos. Asimismo, otras empresas detuvieron su producción por desabastecimiento de sus insumos importados, descrito por Camargo (2020). Debido a la gran incertidumbre, las principales entidades gubernamentales encargadas de emitir las proyecciones macroeconómicas pospusieron sus publicaciones como sostiene Jaramillo y Ñopo (2020). Por otro lado, la cartera de economía desarrolló un plan económico destinando miles de millones de soles para otorgar liquidez a las familias y empresas, según lo informado por el Ministerio de Economía y Finanzas (2020). Medidas que generaron un impulso al Producto Bruto Interno (PBI) hacia el cuarto trimestre del año 2020, tal como lo afirma el Banco Central de Reserva del Perú (2020), escenario reflejado en la oferta y demanda agregada que proponen Varona y Gonzales (2020). En consecuencia, la pandemia impacta negativamente a los agentes económicos.

Palabras clave: COVID-19; Perú; indicadores; economía.

Código de clasificación internacional: 5302.01 - Indicadores económicos.

Cómo citar este ensayo:

Rosales, C., Álvarez, M., \& Lam, I. (2021). Análisis del contexto económico en el Perú a partir del COVID-19. Revista Scientific, 6(21), 237-251, e-ISSN: 2542-2987. Recuperado de: https://doi.org/10.29394/Scientific.issn.2542-2987.2021.6.21.12.237-251

Fecha de Recepción: 16-02-2021
Fecha de Aceptación: 24-06-2021
Fecha de Publicación: 05-08-2021 
Instituto Internacional de Investigación y Desarrollo Tecnológico Educativo INDTEC, C.A.

DOI: https://doi.org/10.29394/Scientific.issn.2542-2987.2021.6.21.12.237-251

OAI-PMH: http://www.indteca.com/ojs/index.php/Revista Scientific/oai

Ensayo Original / Original Essay

\title{
Analysis of the economic context in Peru from COVID-19
}

\begin{abstract}
This essay presents an analysis of the economic situation in Peru in the context of the beginning of the COVID-19 pandemic, given the establishment of a mandatory total quarantine implemented by the government, numerous companies from different sectors had to temporarily suspend their operations, a stage that caused the payment chain to break down and consequently many companies and families did not generate income. Likewise, other companies stopped their production due to a shortage of their imported inputs, described by Camargo (2020). Due to great uncertainty, the main government entities in charge of issuing macroeconomic projections postponed their publications, as argued by Jaramillo and Ñopo (2020). On the other hand, the economy portfolio developed an economic plan allocating billions of soles to provide liquidity to families and companies, as reported by the Ministry of Economy and Finance (2020). Measures that generated a boost to the Gross Domestic Product (GDP) towards the fourth quarter of 2020, as stated by the Central Reserve Bank of Peru (2020), a scenario reflected in the aggregate supply and demand proposed by Varona and Gonzales (2020). Consequently, the pandemic negatively impacts economic agents.
\end{abstract}

Keywords: COVID-19; Peru; indicators; economy. International classification code: 5302.01 - Economic indicators.

\footnotetext{
How to cite this essay:

Rosales, C., Álvarez, M., \& Lam, I. (2021). Analysis of the economic context in Peru from COVID19. Revista Scientific, 6(21), 237-251, e-ISSN: 2542-2987. Recovered from: https://doi.org/10.29394/Scientific.issn.2542-2987.2021.6.21.12.237-251
}

Date Received: 16-02-2021
Date Acceptance: 24-06-2021
Date Publication: 05-08-2021 


\section{Introducción}

El COVID-19 es la enfermedad del síndrome respiratorio agudo grave, el cual fue identificado inicialmente en diciembre del año 2019 en el país de China. Frente al virus, es elemental comprender los elementos importantes de la enfermedad, tales como sus antecedentes, diagnósticos clínicos, y las terapias implementadas. La información respecto al COVID-19 es escasa, sin embargo, la ciencia continúa investigando permanentemente y conforme a sus avances científicos se conocerá más su fisiopatología. Para Rubio, Badia, Mora, Quirós, García y Balibrea (2020): quienes afirman que "los coronavirus son una amplia familia de virus [...]. Son virus esféricos, encapsulados, que contienen ARN monocatenario rodeado por una cubierta proteica" (pág. 311312).

El COVID-19 fue oficializada como enfermedad a nivel internacional el 11 de marzo del año 2020 por la Organización Mundial de la Salud (OMS), tal es así que el gobierno peruano del anterior presidente Martín Alberto Vizcarra Cornejo, emitió el Decreto Supremo N. ${ }^{\circ}$ 008-2020-SA, a través del cual se oficializó la pandemia en el contexto nacional durante un periodo inicial de tres meses, prorrogándose en tres oportunidades más por periodos iguales. Los primeros 90 días de confinamiento, generó que muchas empresas detuviesen su actividad económica en sectores como: construcción, minería, saneamiento, entretenimiento, turismo, gastronomía, educación, industria, manufactura, comercio, transporte público de pasajeros interprovincial y aéreo.

Esta situación causó que se rompiera la cadena de pagos, ya que, al no generar ingresos, las empresas dejaban de pagar a sus proveedores, instituciones financieras, impuestos y generen desempleo; dando como consecuencia que muchas familias perdieran su capacidad de gasto, debiendo mitigar dicha situación con la emisión de diversos bonos; subsidios monetarios otorgados en dos oportunidades, bono de energía eléctrica y bono de agua potable. Siendo fundamental señalar que, en países como Colombia y Chile 
también están formulando estrategias de integración fiscal para garantizar el desarrollo sostenible de su economía, mediante trabajos colaborativos del gobierno; los cuales serán de mucha importancia para superar la crisis.

El incremento de la cartera morosa de las entidades financieras (bancos, financieras, cajas de ahorro y crédito, Edpymes) ha sido uno de los impactos de esta enfermedad, en el sistema financiero. Según Camargo (2020): sostiene que "la globalización económica, que fue el vehículo propagador del virus a través de los viajes [...] por la paralización de la producción generalizada de bienes y servicios, y por ende, del comercio internacional" (pág. 7).

El ensayo trato de reflexionar sobre el contexto de la economía peruana, a causa del COVID-19, reflejado en los indicadores macroeconómicos y microeconómicos del país. La pandemia ha tenido un impacto desfavorable en la situación económica de Perú como la reducción del producto bruto interno (PBI), disminución de la cadena de pagos, incremento temporal de la inflación, aumento de la tasa de desempleo.

\section{Desarrollo}

La economía internacional atraviesa por la peor crisis de los últimos años, a razón de la veloz expansión del virus del SARS-CoV-2. Los países, estados y regiones en un escenario general han asumido un compromiso en aras de fomentar estrictas directrices en materia sanitaria y económica, articulada y coordinada para contrarrestar lo más que se pueda la propagación de la citada enfermedad.

En tal sentido, el Perú no es ajeno a tales circunstancias por lo que actualmente la economía nacional atraviesa por una de sus mayores crisis económicas, lo que ha generado el estancamiento de las actividades empresariales, dadas las medidas de confinamiento o cuarenta. Pasado el primer semestre del año 2020 continúa pendiente la elaboración de los 
Instituto Internacional de Investigación y Desarrollo Tecnológico Educativo INDTEC, C.A.

DOI: https://doi.org/10.29394/Scientific.issn.2542-2987.2021.6.21.12.237-251

OAI-PMH: http://www.indteca.com/ojs/index.php/Revista Scientific/oai

Ensayo Original / Original Essay

informes económicos.

Ante la incertidumbre exacerbada del escenario económico mundial y local, el Banco Central de Reserva del Perú y el Ministerio de Economía y Finanzas decidieron no emitir proyecciones macro oficiales para el segundo semestre del año 2020. Es así como Jaramillo y Ñopo (2020), manifiestan que:

El Banco Central de Reserva del Perú (BCR) ha postergado la publicación de su reporte semanal de inflación que contiene las principales proyecciones macroeconómicas. Por su parte, el Ministerio de Economía y Finanzas (MEF) debía haber publicado, el 31 de marzo, la actualización del marco macroeconómico multianual, pero a mediados de 2020 aún no se cuenta con este documento marco de políticas (pág. 137).

Es preciso señalar, que la solidez macroeconómica en el Perú ha sido determinante para otorgarle el respaldo necesario ante las diversas reglas adoptadas por el ejecutivo en el contexto de la emergencia sanitaria.

Estos aspectos favorables han sido generados por más de 20 años de administración fiscal, lo que ha facilitado a Perú situarse como un estado responsable y solvente, con una alta tendencia de crecimiento, y sin muchos problemas, por ejemplo, en materia de inflación. Sin embargo, el coronavirus ha tenido un impacto negativo en el comportamiento de los bienes y servicios que las empresas están en disposición de producir y vender. De acuerdo con Varona y Gonzales (2020): sostienen que en un nivel más amplio "macroeconómico" el avance de la pandemia, ha creado un efecto de carácter sistémico para la oferta-demanda agregada, ocasionando un fuerte impacto sobre el nivel de la actividad económica.

El gobierno tuvo que implementar distintas políticas económicas para mitigar el impacto en la economía y fue así como lanzó su Plan de reactivación en el cual progresivamente se iban reiniciando las actividades económicas. Una de las facilidades que brindó al sector empresarial en el año 2020, fue el Programa "Reactiva Perú", según Decreto Legislativo N. ${ }^{\circ} 1455$ y su 
modificatoria con el Decreto Legislativo $\mathrm{N} .^{\circ} 1457$, el cual tuvo como objetivo inyectar liquidez a la micro, pequeña y gran empresa para dinamizar la economía del país.

Dada la crisis sanitaria, el gobierno ha implementado medidas económicas desde principios de mayo 2020 para mitigar el descenso de las actividades comerciales y productivas en aras de incrementar los ingresos en las familias. Posteriormente, en el informe del Banco Central de Reserva del Perú (BCRP, 2020), indica que:

En el caso particular del cuarto trimestre, se viene registrando un impulso adicional por el avance de la última fase del plan de reanudación de actividades, la ejecución del segundo bono universal y el crecimiento interanual de la inversión pública por primera vez desde el inicio de la pandemia [...] (pág. 7).

Al respecto se puede manifestar que las limitaciones al libre tránsito de las personas y/o medidas de aislamiento que se necesitan para combatir al COVID-19 representan para varias familias, un golpe altamente significativo de sus probabilidades de obtener rentas.

Figura 1. Perú: Detalle del Plan Económico frente a la COVID- 19.

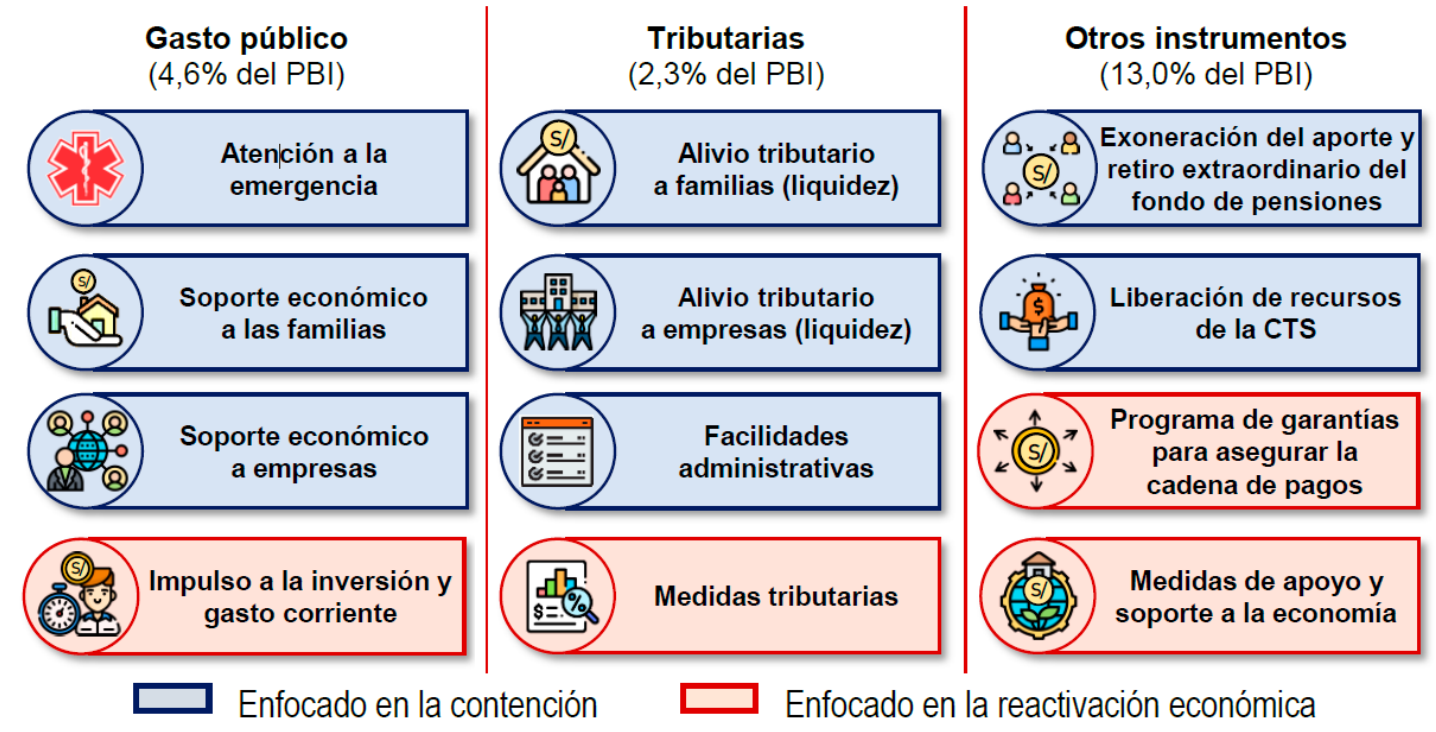

Fuente: Ministerio de Economía y Finanzas (MEF, 2020). 
Instituto Internacional de Investigación y Desarrollo Tecnológico Educativo INDTEC, C.A.

DOI: https://doi.org/10.29394/Scientific.issn.2542-2987.2021.6.21.12.237-251

OAI-PMH: http://www.indteca.com/ojs/index.php/Revista Scientific/oai

Ensayo Original / Original Essay

Cómo se esquematiza en la figura 1, conforme al Ministerio de Economía y Finanzas (MEF, 2020a), se sostiene que:

Por un lado, están las medidas de política fiscal "por encima de la línea" asociadas a gasto público adicional (4,6\% del PBI), así como medidas tributarias $(2,3 \%$ del $\mathrm{PBI})$, que afectarán al resultado económico en la medida que se apliquen y ejecuten. Por otro lado, se están realizando medidas "por debajo de la línea" que incluye otorgar liquidez a las familias y empresas (13,0\% del PBI) (pág. 5).

Por lo tanto, en tiempos inmediatos, dicha coyuntura definitivamente implica severas consecuencias de índole financiera; y en función de la prolongación de la pandemia, podrían reflejarse en mayores efectos en el futuro; vale decir para los hogares en general, que la pandemia tiene fecha inicial, pero es incierto en su fecha de caducidad.

Del mismo modo, el plan Económico ante la emergencia sanitaria posee múltiples instrumentos en materia de gasto público, liquidez y tributaria, que coadyuven a superar la fase de contención de la pandemia y la reestructuración económica, con el objetivo de contrarrestar sus posibles consecuencias.

La primera fase del citado plan es la sujeción oportuna de la contingencia, la misma que persigue una serie de acciones prioritarias tales como, la atención en cuanto a la protección y fortalecimiento del sector salud. Una segunda fase, y no menos importante, es sin duda los hogares o canasta familiar y sus impactos desfavorables que recaen sobre las mismas, por lo que se fomenta la adopción de medidas de cuidado familiar y social, canalizadas a través de un ingente y sólido sistema económico a los hogares calificados como más frágiles a la pandemia.

También otros enfoques relevantes del Plan se direccionan a proveer asistencia económica a diversas organizaciones como Micro y Pequeñas Empresas (MYPES) que dicho sea de paso representan a la mayoría del 
conglomerado empresarial nacional, y suministrarles un respaldo económico que contribuya a su reestructuración por medio de financiamiento o recursos financieros vigentes.

La dirección de la política económica está orientada a desarrollar una estrategia implementada por el Estado para alcanzar, en el corto plazo, una pronta reestructuración de la economía sin olvidar el control de la emergencia sanitaria, y establecer los mecanismos para fortalecer un desarrollo sostenido en el tiempo. Esta reorganización estará alineada a mejorar la inversión y fomentar la productividad y competitividad, los mismos que facilitarán tener una mejor calidad de vida y oportunidades más justas para la sociedad. El Ministerio de Economía y Finanzas (MEF, 2020b), expone que:

En los tres últimos años, los esfuerzos de política y administración tributaria para combatir la evasión y elusión de impuestos han permitido la recuperación sostenida de los ingresos fiscales. Sin embargo, debido a la crisis mundial originada por la COVID-19, en 2020 se experimentaría una de las caídas más importantes de la recaudación de ingresos de la historia, y un retroceso hacia niveles no vistos desde hace 4 años, afectados principalmente por la caída de la actividad económica y los efectos de los aplazamientos de los impuestos (pág. 107).

Figura 2. Comportamiento de Ingresos del Gobierno Central.

Ingresos del Gobierno General, 2019-2020 (Miles de millones de S/)

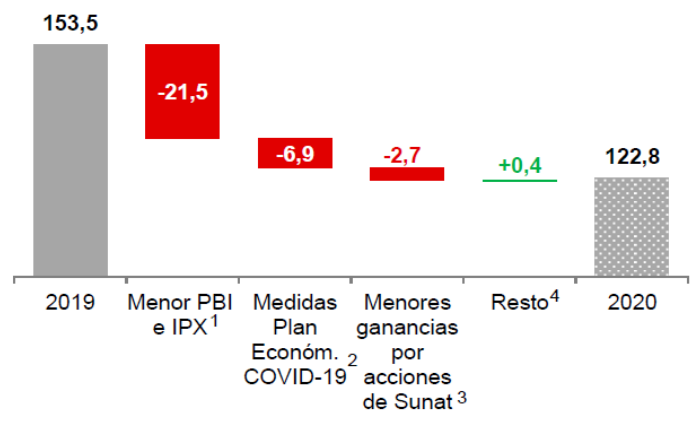

Crecimiento de los ingresos tributarios del Gobierno Central (ITGC), 2020

(Contribución real)

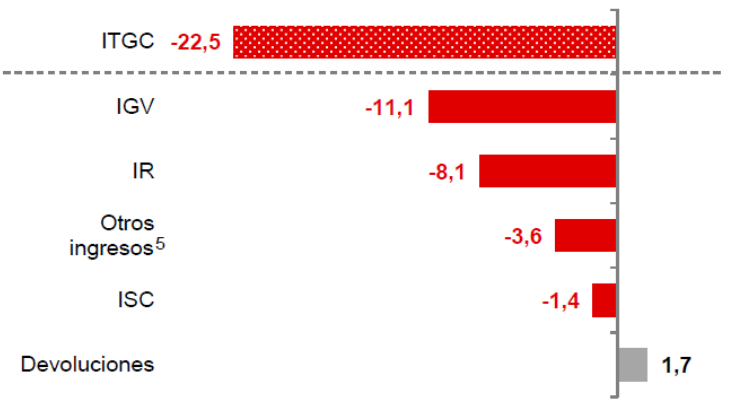

Fuente: Ministerio de Economía y Finanzas (MEF, 2020). 
Cómo se refleja en la figura 2, según el Ministerio de Economía y Finanzas (MEF, 2020c): "la reducción de los ingresos tributarios del Gobierno Central $(-22,5 \%$ real) reflejará tanto la menor actividad económica, como el efecto temporal de las prórrogas otorgadas al pago de impuestos [...]" (pág. 109). Situación que dio origen a un mayor endeudamiento público externo, los cuales han sido destinados a subvencionar en cierta medida todos los proyectos propuestos con fines de contrarrestar la crisis.

Las implicancias económicas han perjudicado directamente la recaudación tributaria en el año 2020 y, por ende, su efecto culminará en la medida en que se reinicie el movimiento empresarial. El gasto será orientado a consolidar los diversos campos tales como salud, educación, infraestructura pública; factores importantes y de esta manera brindar un buen servicio de calidad a la ciudadanía. Estas acciones han contribuido a que los bonos soberanos cuenten con intereses bajos, lo que refleja la credibilidad del sistema financiero.

Por consiguiente, los impactos adversos del coronavirus en las finanzas públicas se ven traducidas en daños considerables hacia las estadísticas financieras, por ejemplo: el riesgo país y calificaciones crediticias. Consecuentemente, el Perú sobresale por conservar índices y escalas altamente relevantes, mostrando la seguridad del sector financiero. Conforme al Instituto Nacional de Estadística e Informática (INEI, 2020): en el Perú, las "empresas operativas, según problemas financieros debido al impacto del COVID-19" (pág. 12); el 81,4\% presentaron algún problema financiero y el $18,6 \%$ no presentaron problemas financieros.

El rendimiento económico ha tenido una reducción importante correspondiente al periodo noviembre del año 2020, representando el menor cambio desfavorable desde principios del coronavirus, a causa de la evolución favorable de los rubros de Construcción, agropecuario, telecomunicaciones, financieros, gestión pública y defensa; sin embargo, algunas áreas reflejaron 
un buen nivel de solvencia económica, tales como: restaurantes, hospedaje, transporte, mensajería y almacenamiento. La cartera de economía y finanzas autorizó la inyección de recursos financieros por miles de millones de soles, con la finalidad de contrarrestar el impacto económico de la crisis sanitaria y así dinamizar el flujo económico de las familias y empresas en el país. Para lo que aduce Canseco (2020): que "la ministra de Economía, María Antonieta Alva, y el presidente Martín Vizcarra han tomado muchas decisiones para afrontar la crisis, como el empleo de 30 mil millones de soles, que significan 12 puntos del PBI" (pág. 10).

Por otro lado, nace una nueva incógnita que es saber si se cuentan con suficiente respaldo de ahorro nacional para poder asumir una mayor extensión de políticas para contrarrestar, reducir y restaurar los impactos ocasionados. Siendo oportuno precisar que, gracias a la estable política económica del país, a la sostenibilidad económica de los últimos tiempos, la nación cuenta con un significativo margen de ahorro interno, solvencia económica y fiscal, que facilita la implementación de medidas contra el virus SARS-CoV-2.

\section{Conclusiones}

El contexto económico de la emergencia sanitaria en el Perú ha sido desfavorable, evidenciada en la reducción de sus principales indicadores económicos como el producto bruto interno (PBI), la inflación, la tasa de desempleo, la población económicamente activa; sin embargo, el país se distingue por conservar un estado de cierta estabilidad, lo que genera seguridad a las empresas privadas en el contexto del sistema financiero, visualizándose sus cualidades macroeconómicas a nivel país, y consecuentemente su firme condición fiscal antes y durante de la enfermedad.

El coronavirus ha generado una serie de impactos altamente adversos en las familias $u$ hogares, dado que las empresas privadas han sido perjudicadas por la reducción de sus niveles de ventas e inclusive el cese de 
actividades; originando el despido masivo de su personal, en los periodos de las cuarentenas o confinamiento. Las familias no cuentan con liquidez o disponibilidad de recursos para asumir sus obligaciones inmediatas.

Post COVID-19, deja como desafíos en el tema económico, el fortalecimiento de las cuentas gubernamentales con el propósito de salvaguardar el desarrollo sostenible del Perú, pero procurando no producir consecuencias negativas en las finanzas públicas. Para tal fin y en aras de alcanzar el propósito de la integración fiscal, el país cuenta con elementos orientados a perfeccionar con eficiencia, eficacia y economía el gasto estatal y el aumento de los ingresos, partiendo de la mejora de la gestión y administración pública.

\section{Referencias}

BCRP (2020). Reporte de Inflación diciembre 2020: Panorama actual y proyecciones macroeconómicas 2020-2022. 1-160, e-ISSN: 17285739. Perú: Banco Central de Reserva del Perú. Recuperado de: https://www.bcrp.gob.pe/docs/Publicaciones/ReporteInflacion/2020/diciembre/reporte-de-inflacion-diciembre-2020.pdf Camargo, D. (2020). Acerca de las perspectivas de la economía colombiana en tiempos de coronavirus sars-CoV-2 (COVID-19). Revista Facultad de Ciencias Económicas: Investigación y Reflexión, 28(1), 7-8, e-ISSN: 0121-6805. Recuperado de:

https://www.redalyc. org/articulo.oa?id=90965263001

Canseco, R. (2020). Economía Peruana: Contención y Reactivación en tiempos del COVID-19. Primera edición. Perú: Fondo editorial Universidad San Ignacio de Loyola. Recuperado de:

http://repositorio.usil.edu.pe/bitstream/USIL/9889/1/2020 DiezCanseco Econom\%c3\%ada-Peruana.pdf

INEI (2020). Lima Metropolitana: Encuesta de opinión sobre el impacto 
Instituto Internacional de Investigación y Desarrollo Tecnológico Educativo INDTEC, C.A.

DOI: https://doi.org/10.29394/Scientific.issn.2542-2987.2021.6.21.12.237-251

OAI-PMH: http://www.indteca.com/ojs/index.php/Revista Scientific/oai

Ensayo Original / Original Essay

del COVID-19 en las empresas. Lima, Perú: Instituto Nacional de Estadística e Informática. Recuperado de:

http://m.inei.gob.pe/media/MenuRecursivo/boletines/resultados-

encuesta-covid-lima metropolitana-2020.pdf

Jaramillo, M., \& Ñopo, H. (2020). El impacto del Covid-19 sobre la economía

peruana. Economíaunam, 17(51), 136-146, e-ISSN: 2448-8143.

Recuperado de:

http://revistaeconomia.unam.mx/index.php/ecu/article/view/552

MEF (2020a,b,c). Marco Macroeconómico Multianual 2021-2024. Aprobado

en Sesión de Consejo de Ministros. Perú: Ministerio de Economía y

Finanzas. Recuperado de:

https://www.mef.gob.pe/pol econ/marco macro/MMM 2021 2024.pdf

Rubio-Pérez, I., Badia, J., Mora-Rillo, M., Martín, A., García, J., \& Balibrea, J.

(2020). COVID-19: Conceptos clave para el cirujano. Cirugía Española, 98(6), 310-319, e-ISSN: 0009-739X. Recuperado de:

https://doi.org/10.1016/j.ciresp.2020.04.009

Varona, L., \& Gonzales, G. (2021). Dynamics of the impact of COVID-19 on the economic activity of Peru. PLOS ONE, 16(1), 1-30, e-ISSN: 19326203. Recuperado de: https://doi.org/10.1371/journal.pone.0244920 


\section{Ensayo Original / Original Essay}

\section{Carlos Antonio Rosales Enríquez}

e-mail: crosales1000@gmail.com

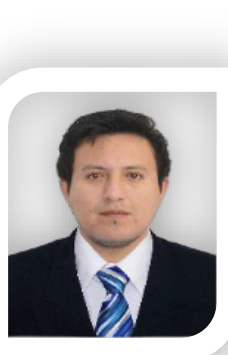

Nacido en Chimbote, Perú, el 14 de agosto del año 1987.

Soy docente a tiempo completo en la Universidad Tecnológica del Perú (UTP), filial Chimbote; de formación Contador Público por la Universidad César Vallejo (UCV);

Colegiado y Certificado por el Colegio de Contadores

Públicos de Áncash; con Maestría en Administración de Negocios y Relaciones Internacionales MBA por la Universidad César Vallejo; egresado del Doctorado en Administración por la Universidad César Vallejo; especialista en Banca, Finanzas y Normas Internacionales de Información Financiera (NIIF); asesor y consultor externo; docente universitario; amante de la lectura financiera y el deporte. 


\section{Ensayo Original / Original Essay}

\section{Mary Sabeth Álvarez Silva \\ e-mail: marysabethalvarez@hotmail.com}

Nacida en Chimbote Perú, el 21 de febrero del año 1985.

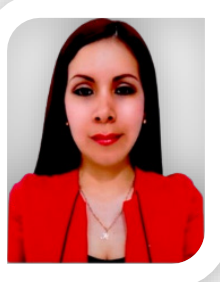

Soy docente a tiempo completo en la Universidad Tecnológica del Perú (UTP), sede Chimbote; y auditor financiero en consultoría y asesoría privada; de formación, Contador Público con 11 años de experiencia, licenciada por la Universidad Privada del Norte (UPN), perteneciente al quinto superior; auditor Independiente Certificado por el Colegio de Contadores Públicos de la Libertad; y maestro en Contabilidad con mención en Tributación de la Universidad Católica los Ángeles de Chimbote (ULADECH); con experiencia en el sector público y privado, en los rubros; educación universitaria, administración tributaria, gobiernos locales, siderúrgica y auditoría financiera. 


\section{Ensayo Original / Original Essay}

\section{Ingrid Cristina Lam Flores}

e-mail: ilamflo@hotmail.com

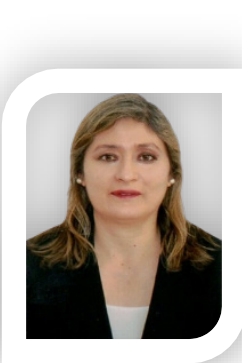

Nacida en Chimbote, Perú, el 22 de Julio del año 1978.

Soy docente a tiempo completo de la Universidad Tecnológica del Perú (UTP), filial Chimbote; de formación Contadora Pública por la Universidad San Pedro (USP), Colegiada y Certificada por el Colegio de Contadores Públicos de la Libertad; con Maestría en Administración de Negocios MBA Executive por la Universidad César Vallejo (UCV), Trujillo; certificada en Evaluación de Competencia de Capital Humano, por el Consejo Nacional de Normalización y Certificación de Competencias Laborales (CONOCER) y la Secretaria de Educación Pública de México; especialista en Finanzas, Gestión Pública y Modernización del Estado. 